\title{
Inflation Targeting and Macroeconomic Stability in a Post Keynesian Economy
}

\author{
Gilberto Tadeu Lima \\ Department of Economics \\ University of São Paulo, Brazil \\ giltadeu@usp.br \\ and \\ Mark Setterfield \\ Department of Economics \\ Trinity College \\ Hartford, CT USA \\ mark.setterfield@trincoll.edu
}

\begin{abstract}
This paper investigates the compatibility of inflation targeting and Post Keynesian economics by examining the macroeconomic consequences of a variety of policy reaction functions for an economy that is explicitly Post Keynesian in character. It is shown that in this Post Keynesian environment, it is possible for the policy authorities to both set and achieve an inflation target without adverse consequences for the real economy, as long as an appropriate policy mix is chosen. One of the key results of the paper is that orthodox policy regimes do not provide appropriate policy mixes. Indeed, the more orthodox the policy regime becomes, the less viable is inflation targeting in a Post Keynesian economy.
\end{abstract}

Keywords: Inflation targeting, monetary policy, incomes policy, macroeconomic stability.

Resumo: O artigo analisa a compatibilidade do regime de meta de inflação com a economia Pós-Keynesiana através do exame das implicações macroeconômicas de uma variedade de funções de reação de política em uma macroeconomia de caratér explicitamente Pós-Keynesiano. Mostra-se que nesse ambiente, é possível para as autoridades econômicas estabelecer e alcançar uma meta de inflação sem implicações adversas para o lado real, desde que uma combinação adequada de políticas seja escolhida. Um dos principais resultados do artigo é que regimes de política econômica ortodoxos não fornecem combinações de política adequadas. De fato, quanto mais ortodoxo se torna o regime de política econômica, menos viável se torna o regime de meta de inflação em uma economia Pós-Keynesiana.

Palavras-chave: Meta de inflação, política monetária, política de rendas, estabilidade macroeconômica.

J.E.L. Classification Codes: E12, E61, E63, E64

Classificação Anpec: Área 3 - Macroeconomia, Economia Monetária e Finanças 


\section{Introduction}

The idea of inflation targeting is anathema for many Post Keynesian economists, because of concern with the potential real costs (in terms of foregone output and employment) of a singular focus on low inflation as the goal of macroeconomic policy. ${ }^{1}$ This concern becomes acute when inflation targeting is understood to involve not just the pursuit of low inflation enshrined in a target that public policy authorities credibly and accountably commit to achieve, but also - and more specifically - the dedicated use of monetary policy to achieve this goal. ${ }^{2}$ But according to Setterfield (2006a), Post Keynesian concerns with inflation targeting can be finessed as soon as it is recognized that inflation targeting can be accommodated even in an economy in which output and employment do not automatically gravitate towards unique supplydetermined equilibria. This can be achieved simply by using more and different policy instruments to reconcile the pursuit of low inflation with other (real) macroeconomic policy goals. ${ }^{3}$

The purpose of this paper is to engage in further consideration of the relationship between inflation targeting and Post Keynesian economics. The paper takes as its starting point the Extended Post Keynesian Model (EPKM) developed by Setterfield (2006a), but identifies two important shortcomings of this model. First, it does not explicitly take into account the role of expectations in the inflation process. This is a curious omission given the central importance of expectations in the determination of macroeconomic outcomes in Post Keynesian theory. Second, and for the purposes of this paper most importantly, the model provides no account of the effects of different policy reaction functions on the effects of inflation targeting and the stability of macroeconomic equilibrium. In other words, it fails to recognize the range of reaction functions that can result from the discretionary choices of policy authorities concerned with both output and inflation targets, and the extent to which these discretionary choices can enhance or diminish the claim that inflation targeting is compatible with Post Keynesian economics. While this kind of evaluation of the macro performance of different reaction functions has been done extensively in the mainstream literature, this literature uses a structurally different macro model and confines attention to monetary policy. We, however, examine the impact of both monetary and non-monetary policy reaction functions on the possibilities for successful inflation targeting and the stability of macroeconomic equilibrium in a Post Keynesian economy. Moreover, in resolving the shortcomings of Setterfield (2006a) alluded to above, we are able to demonstrate two important results. First, that the potential compatibility of inflation targeting with a Post Keynesian economy extends to a broader range of policy interventions than was originally envisaged by Setterfield (2006a). And second, that the more orthodox the policy blend becomes in a Post Keynesian economy, the more adverse are the consequences for macroeconomic stability and the viability of inflation targeting.

The remainder of this paper is organized as follows. In section 2, we outline the basic model used throughout this paper, which modifies Setterfield's (2006a) EPKM by formally modelling the impact of expectations on the inflation process. Section 3 then examines the impact of different policy reaction functions on the possibilities for successful inflation targeting and the stability of macroeconomic equilibrium in a Post Keynesian economy. Finally, section 4 offers some conclusions.

\section{The Basic Model}

The basic model on which the analysis in this paper is based can be stated as follows:

\footnotetext{
${ }^{1}$ Rochon and Rossi (2006) and Atesoglu and Smithin (2006) also call attention to the potentially adverse effects of inflation targeting on the wage share of income.

${ }^{2}$ See, for example, Mishkin (2002) for this more stringent definition of inflation targeting.

${ }^{3}$ The accommodation achieved in Setterfield (2006a) thus results essentially from application of Tinbergen's (1952) principle, that there needs to be as many policy instruments as policy goals. Note also that this accommodation establishes inflation targeting as just one objective of macroeconomic policy, rather than its only objective, and makes no presuppositions about the particular use to which monetary policy should be put. See also Michl (2006) on the importance of Tinbergen's principle in models of inflation targeting. Setterfield (2006a) is not the first or only author to claim that inflation targeting is compatible with Post Keynesian economics: see also Davidson (2006), Sawyer (2006) and Palley (2006a, 2006b).
} 


$$
\begin{aligned}
& y=y_{0}-\delta r \\
& p=\beta+\varphi p^{e}+\alpha y+\theta Z \\
& \dot{r}=\lambda\left(y-y^{T}\right) \\
& \dot{Z}=-\mu\left(p-p^{T}\right)
\end{aligned}
$$

where $y$ denotes the level of real output, $y_{0}$ represents non-interest sensitive components of aggregate spending, $r$ is the real interest rate, $p$ and $p^{e}$ are the actual and expected rates of inflation, respectively, $Z$ captures the willingness and ability of workers to bid up the rate of growth of nominal wages independently of the level of economic activity, $y^{T}$ denotes the policy authorities' target level of real output and $p^{T}$ their target rate of inflation. Equation [1] is simply an IS curve, equation [2] is an expectations-augmented Phillips curve and equations [3] and [4] are policy reaction functions. ${ }^{4}$ Equation [3] describes the conduct of monetary policy which, in keeping with the Post Keynesian theory of endogenous money, takes the form of an interest rate operating procedure. ${ }^{5}$ The instrument for achieving changes in $Z$ in equation [4], meanwhile, must ultimately be some form of incomes policy, where incomes policies are defined as formal and/or informal institutions that frame and mediate aggregate wage and price setting behaviour in such a way as to reduce conflict over income shares and better reconcile conflicting income claims (Setterfield, 2006b). ${ }^{6}$ As discussed by Setterfield (2006b), incomes policies so-defined can be either cooperative or coercive, depending on whether the objective is to seek a mutually satisfactory reconciliation of competing income claims, or to achieve such reconciliation by so configuring institutions as to force one party (either firms or workers) to accept the distributional claims of the other. Hence the precise policy pursued in order to, for example, reduce $Z$ might involve an effort to centralize wage bargaining, the creation of a tax-based or market anti-inflation plan (see, for example, Colander, 1986), or changes in labour law designed to reduce the job-security of workers. ${ }^{7}$ The perspective adopted here is that any incomes policy will ultimately constitute a codification of the distribution of power in society. ${ }^{8}$ Hence cooperative incomes policies can arise when labour has sufficient power, but there can also be coercive incomes policies that succeed in containing inflation, but are essentially an expression of capital's power vis a vis labour and its concomitant

\footnotetext{
${ }^{4}$ We abstract from the distinction between short- and long-term interest rates. We note also that, in practice, the interest elasticity of aggregate spending may well be small. The precise form taken by the policy functions in [3] and [4] is subject to explicit scrutiny in section 3 below. For the time being, we need only note that, as will be demonstrated below, equations [3] and [4] are sufficient to resolve the "inflation targeting dilemma" (associated with the real costs of inflation targeting) alluded to in the introduction, and that arises in a Post Keynesian model whenever policy authorities are (a) exclusively committed to inflation targeting and (b) inclined to think of inflation as a strictly demand-pull phenomenon that can only be remedied by depressing aggregate demand. See Atesoglu and Smithin (2006), Davidson (2006) and Setterfield (2006a) for discussion of this dilemma.

${ }^{5}$ The control over longer rates that results from manipulation of the short rate may, of course, be imperfect, while there also exists the zero lower bound constraint on the nominal interest rate. We abstract from both of these issues in what follows. Note that implicit in [3] is the notion that it is appropriate to use monetary policy (rather than, say, fiscal policy) to target real output. In the context of this paper, the choice of policy instrument in [3] is motivated by two factors. First, it serves to draw attention to the real effects of monetary policy in a Post Keynesian economy. Second, as will become clear in section 3, it facilitates straightforward comparison and contrast of Post Keynesian and orthodox policy regimes, and thus serves a useful pedagogical purpose. Eq. [3] is thus not intended to imply that monetary policy is necessarily superior to fiscal policy as an instrument for influencing real activity. ${ }^{6}$ It might be objected that the manipulation of an incomes policy so-defined is likely to prove difficult in the short-run time horizon envisaged by the model in equations [1], [2a] and [3]- [4]. We would contend, however, that whilst the initial construction of an incomes policy is likely to be time consuming, its subsequent manipulation need not be. For example, in the classic tax-based incomes policy proposed by Wallich and Weintraub (1971), the ultimate instrument of policy is a tax rate that should be amenable to change (at least within limits) even in the short run.

${ }^{7}$ As should be clear from these examples, even policies that achieve similar reductions in $Z$ may vary tremendously in the extent to which they are deemed equitable.

${ }^{8}$ The precise form of an incomes policy may also be influenced by factors such as the size of an economy and/or the homogeneity of its population.
} 
ability to impose its preferred distribution of income on labour. ${ }^{9}$ Indeed, we would argue that the success of any incomes policy depends very much on its compatibility with the existing distribution of power in society, making policy design in this instance as much a socio-political as an economic exercise (on which, see Lima, 2004).

In keeping with the Post Keynesian structure of this model, we make no assumption that the coefficients in equations [1] - [4] nor even the precise form of these structural equations are time-invariant. We do, however, abstract from these dynamics in what follows, although as will become clear, not without taking into account the behavioural ramifications of their existence. ${ }^{10}$

Equation [2] makes the structural model above identifiably Post Keynesian in spirit. ${ }^{11}$ The assumption that $\varphi<1$ (which is consistent with the notion that workers are unable to automatically fully index expected inflation into nominal wage growth) and the absence of any reference to a supply-determined equilibrium or "natural" level of output in the Phillips curve are consistent with four essential tenets of Post Keynesian macroeconomics: the idea that the wage bargain is conducted in nominal terms, with real wages being determined only after the wage bargain is complete; the non-neutrality of money; the central role of aggregate demand in determining the equilibrium values of real variables; and the importance of cost-push inflation (the notion that changes in the rate of growth of costs - and in particular, wage inflation associated with conflict over the functional distribution of income - are an important source of inflation). The correspondence between equation [2] and this last tenet is reinforced by the inclusion of the variable $Z$ in the Phillips curve, which is exclusively associated with the capacity of conflicting claims over nominal income to create inflation. Hence suppose there exists an incomes policy or "social bargain" (Cornwall and Cornwall, 2001) that creates a conventional and mutually acceptable functional distribution of income that both capital and labour are content to maintain. This will reduce the willingness of workers to bid up wages at any given level of economic activity in an effort to translate the market power vested in them by the latter into a larger share of income. ${ }^{12}$ In terms of equation [2], the result will be a lower value of $Z$ and hence, ceteris paribus, a lower rate of inflation.

The model in equations [1] [4] differs from Setterfield's (2006a) EPKM only by virtue of its inclusion of the expected rate of inflation in the Phillips curve. Note, moreover, that if $p^{e}=p_{-1}$ (i.e., if we postulate adaptive expectations), then the model above becomes identical to Setterfield's EPKM. Agliari et al (2006) argue that the rational expectations revolution was too quick to reject adaptive expectations on the basis of linear dynamical models, and that the richer array of outcomes associated with non-linear dynamical systems suggests many situations in which the adaptive expectations hypothesis is a defensible expectations schema. However, the fact remains that there is no necessary or obvious connection between adaptive

\footnotetext{
${ }^{9}$ See Setterfield (2006b) for the argument that an incomes policy of this sort has operated in the US economy over the last $15-20$ years.

${ }^{10}$ In this way, we are "locking up without ignoring" (Kregel, 1976) some of the dynamics of a Post Keynesian economy in an effort to focus attention on other dynamics in a "conditionally" or "provisionally" closed system (see Setterfield, 1997, 2003 and Chick and Caserta, 1997 respectively). Closure is conditional or provisional in the precise sense that it depends on our ability to treat as unchanging certain features or elements of the economy that are, in principle, subject to change over time. Note that the need to introduce such conditional closure cannot be avoided by simply adding more equations until our model is expressed in terms of Lucasian "deep parameters" and absolute closure is achieved. These "deep parameters" are assumed not to exist and the economy is, instead, treated as an open system (see Lawson, 1995). Indeed, this is understood to be the source of the fundamental uncertainty that decision makers face in a Post Keynesian economy.

11 Appendix I formally demonstrates that equation [2] can be thought of as a linear approximation of the reduced form of a conflicting-claims model of inflation. Rowthorn (1977) develops an early model of conflict inflation, while Lavoie (1992, chpt. 7) and Burdekin and Burkett (1996) provide surveys of the conflicting claims approach to inflation.

${ }^{12}$ Note that firms may display a proclivity to increase prices independently of changes in costs in pursuit of distributional goals, so there is no intent here to suggest that workers are uniquely responsible for inflationary pressures. Instead, in the model developed above we are merely abstracting from the behaviour of firms just described for the sake of simplicity.
} 
expectations and Post Keynesian economics. ${ }^{13}$ As such, the inclusion of the term $p^{e}$ in equation [2] is significant because it demands explicit consideration of expectations formation and the influence of expectational factors on inflation from a Post Keynesian perspective.

The Post Keynesian theory of inflation expectations that we use to complete the "conditional" closure of the model in equations [1] - [4] is based on the work of Dequech (2000) and can be stated as follows:

$$
p^{e}=E(p \mid \Omega)
$$

where:

$$
\Omega^{T}=[\Psi \Theta \Phi]
$$

with $\Psi$ denoting decision makers' information set, $\Theta$ denoting their animal spirits and $\Phi$ denoting their creativity. The basic theory here is that in an environment of uncertainty in which there is no time-invariant true model on which expectations can be based, the latter are instead a product of what decision makers do know (or think they know) about the structure of the inflation process (the incomplete information set, $\Psi$ ), the capacity of decision makers to anticipate innovations that produce novel change in the structure of the inflation process (captured by their creativity, $\Phi)$ and decision makers' animal spirits $(\Theta)$, which influence expectations via their effects on "spontaneous optimism" (see Dequech, 2000, p.161). Hence as in the first of the two equations immediately above, $p^{e}$ is conditional on the vector $\Omega$ that captures each of these influences - information, creativity and animal spirits - on expectations.

With expectations so-specified, the expectations-augmented Phillips curve becomes:

$$
p=p(E(p \mid \Omega), \Theta, y, Z)
$$

Notice that in addition to their impact on inflation expectations, animal spirits also exert a second and separate influence on the actual rate of inflation. This takes into account the fact that in an environment of uncertainty, behaviour (in this case wage and price setting) is influenced not only by expectations themselves, but also by the confidence with which decision makers hold these expectations. In this way, a change in animal spirits, by altering decision makers aversion to and/or perception of uncertainty, can affect the confidence that they have in any given set of expectations and hence the behaviour based on these expectations (Dequech, 2000, p.161). This is an example of what Gerard (1995) identifies as the "two-step" nature of decision making under uncertainty, whereby decision makers must first formulate a "most probable forecast" (captured by $p^{e}$ above), and then assess the "credence" of this forecast before deciding how to act. In this way, anything that affects the "credence" of a forecast can alter behaviour quite independently of changes in the forecast itself - which is precisely what is allowed for in the expectations-augmented Phillips curve above. ${ }^{14}$

\footnotetext{
${ }^{13}$ Although it could, of course, be argued that the Post Keynesian model in equations [1] - [4] is a local, linear approximation of a non-linear dynamical system, in which case the arguments of Agliari et al (2006) can be explicitly connected to the Post Keynesian project. However, it is less clear that in the environment described by Agliari et al (2006), Post Keynesian economists would agree that an adaptive expectations mechanism suffices to fully describe the expectations formation process, much less the way in which decision makers will proceed to behave once they have formed expectations.

${ }^{14}$ The obvious contrast here is with the canonical version of rational expectations, formed as $p^{e}=E\left(p \mid \Psi^{\prime}\right)$, where $\Psi^{\prime}$ constitutes a complete information set (including the time-invariant "true" model of the inflation process), and factors such as animal spirits exert no influence on behaviour either indirectly (via $p^{e}$ ) or directly (as in the expectations-augmented Phillips curve above). The key characteristic of rational expectations so-defined is that they cannot be systematically wrong. In contrast, expectations formed under uncertainty on the basis of the incomplete information set $\psi$ can be systematically wrong, and decision makers are aware of this - hence the role and importance of the second step in the decision making process described above.
} 
In order to achieve conditional closure we must still specify the precise form of $E(p \mid \Omega)$ and describe the behaviour of $\Theta$. The latter is achieved by once again "locking up without ignoring" a feature of the dynamics of our model by assuming that $\Theta=\bar{\Theta} \cdot{ }^{15}$ In order to specify $E(p \mid \Omega)$, meanwhile, we appeal to the claims originally made by Keynes $(1936,1937)$ that, in an environment of uncertainty, expectations are likely to be heavily influenced by recent events and social conventions. Emphasis on the latter seems to be particularly appropriate in the current context given that in the model described in equations [1] - [4], macroeconomic policy is rule-based (equations [3] and [4]) and one of these policy rules makes explicit reference to the conventional construct $p^{T}$. What we are suggesting here is that: (a) in general, policy rules are excellent examples of social conventions, so that by specifying transparent policy rules, policy makers can perform an intrinsically useful function by creating "conventional anchors" for expectations formed under uncertainty; and (b) inflation targeting - the pursuit of low inflation enshrined in a clearly announced target that public policy authorities credibly and accountably commit to achieve - is a specific example of how policy authorities can engage in the creation of one such "conventional anchor" for expectations. ${ }^{16}$ In light of all this, then, we write:

$$
E(p \mid \Omega)=\kappa \sum_{i=1}^{n} \Phi(1-\Phi)^{i-1} p_{-i}+(1-\kappa) p^{T}
$$

where $\Phi<1$. In other words, expected inflation is modelled as a weighted average of the policy convention, $p^{T}$, and a distributed lag of past inflation rates. The parameter $\kappa$ can be thought of as decreasing in the credibility of the policy authorities' commitment to achieve $p^{T}$, so that in the limit, $\kappa=0$ and we can write: ${ }^{17}$

$$
E(p \mid \Omega)=p^{T}
$$

This expression, together with the assumption made about the behaviour of animal spirits, yields:

$$
p=p\left(p^{T}, \bar{\Theta}, y, Z\right)
$$

Finally, giving the expectations-augmented Phillips curve stated above an explicit linear functional form, we arrive at:

$$
p=\beta+\varphi p^{T}+\alpha y+\theta Z
$$

By combining equation [2a] with equations [1], [3] and [4] stated earlier, we are now in a position to analyse the effects of inflation targeting in the Post Keynesian economy modelled above. First, note that it follows from [1] that:

$$
\dot{y}=-\delta \dot{r}
$$

which, using [3], can be written as:

\footnotetext{
${ }^{15}$ Alternatively, $\Theta=\bar{\Theta}$ can be interpreted as a "equilibrium of action" (Chick, 2002), in which even in the absence of evidence confirming the realization of expectations, decision makers find no basis in current economic events to change the credence they attach to these expectations.

${ }^{16}$ Note that in this way, before we have even begun to explore the macroeconomic effects of inflation targeting, the theory of decision making under uncertainty draws attention to one way in which inflation targeting might prove useful in the context of a Post Keynesian economy, by creating a degree of stability (conditional on the salience and durability of the conventions of inflation targeting) in inflation expectations and wage and price setting behaviour that need not otherwise exist.

${ }^{17}$ The expression that follows is identical to that posited by Kapadia (2005) as an alternative to "backward looking" expectations rules in New Keynesian models. For Kapadia, however, "inflation-target expectations" are only formed by near-rational decision makers who cannot afford to form rational expectations. In the environment of fundamental uncertainty with which we are dealing, however, no decision maker is able to form rational expectations, and hence the expression for inflation expectations that follows can be treated as universal.
} 


$$
\dot{y}=-\delta \lambda\left(y-y^{T}\right)
$$

Similarly, equation $[2 \mathrm{a}]$ yields:

$$
\dot{p}=\alpha \dot{y}+\theta \dot{Z}
$$

Combining this expression with both [4] and [5], we arrive at:

$$
\dot{p}=-\alpha \delta \lambda\left(y-y^{T}\right)-\theta \mu\left(p-p^{T}\right)
$$

We can now solve for equilibrium by imposing the equilibrium conditions $\dot{y}=\dot{p}=0$ on equations [5] and [6]. This yields the isoclines:

$$
y=y^{T}
$$

and:

$$
y=\left(y^{T}+\frac{\theta \mu}{\alpha \delta \lambda} p^{T}\right)-\frac{\theta \mu}{\alpha \delta \lambda} p
$$

It follows directly from [7] that $y^{*}=y^{T}$, and using this result in conjunction with [8] we find that $p^{*}=p^{T}$ (where an asterisk denotes the equilibrium value of a variable). ${ }^{18}$ Finally, note that the equilibrium configuration so identified is stable. This can be verified by writing [5] and [6] in matrix form as:

$$
\left[\begin{array}{c}
\dot{y} \\
\dot{p}
\end{array}\right]=\left[\begin{array}{cc}
-\delta \lambda & 0 \\
-\alpha \delta \lambda & -\theta \mu
\end{array}\right]\left[\begin{array}{l}
y \\
p
\end{array}\right]+\left[\begin{array}{c}
\delta \lambda y^{T} \\
\alpha \delta \lambda y^{T}+\theta \mu p^{T}
\end{array}\right]
$$

and noting that $|J|=\delta \lambda \theta \mu>0$ whilst $\operatorname{tr}(J)=-(\delta \lambda+\theta \mu)<0$. The substance of these results is as follows. In the economy described by equations [1], [2a], [3] and [4], the policy authorities set and pursue output and inflation targets that are, in turn, revealed to comprise the stable equilibrium configuration of the economy. This establishes what Setterfield (2006a) defines as the full compatibility of inflation targeting with the underlying structure of the economy: not only are the policy authorities able to both set and achieve an inflation target (establishing the partial compatibility of inflation targeting with the economy), they are able to do so without real costs (in terms of the equilibrium level of output) and hence without thwarting the achievement of any output target set independently of $p^{T} .{ }^{19}$ To see this latter result, consider Figure 1 below, which plots the isoclines in equations [7] and [8] assuming two different target rates of inflation. As is clear from Figure 1, decreasing the target rate of inflation (from $p_{1}^{T}$ to $p_{2}^{T}$ ) changes the equilibrium configuration of the economy, but only by altering the equilibrium rate of inflation (and in a manner consistent with the new inflation target): the equilibrium level of output remains consistent with the authorities' output target, $y^{T}$.

\footnotetext{
${ }^{18}$ Note that, by referring back to equations [1] and [2a], we can use these results to infer the equilibrium values of $r$ and $Z$, which are $r^{*}=\left(y_{0}-y^{T}\right) / \delta$ and $z^{*}=\left[(1-\varphi) p^{T}-\beta-\alpha y^{T}\right] / \theta$, respectively. Note that $r^{*}$ is decreasing in $y^{T}$ : the higher the target level of output, the smaller the equilibrium rate of interest must be. This is in keeping with the inverse relationship between $y$ and $r$ in equation [1]. Meanwhile, $Z^{*}$ is increasing in $p^{T}$ and decreasing in $y^{T}$ : a higher inflation target means that policy can relax its efforts to restrain either the ability or willingness of workers to increase the rate of growth of nominal wages, whilst a higher output target requires more vigilance in this regard, because of the direct relationship between $y$ and $p$ in equation [2a].

${ }^{19}$ Note that an output target that is dependent on $p^{T}$ - specifically, that respects the direct relationship between $p$ and $y$ in [2a] - can always be achieved even if we replace [4] with $\dot{Z}=0$. But from our point of view this result is trivial since it makes the level of output entirely subservient to the policy authorities' inflation target, and thus amounts to no more than the dedicated use of macroeconomic policy to pursue low inflation (as envisaged by mainstream proponents of inflation targeting such as Mishkin, 2002 ) at all costs. It is thus not equivalent to what is identified by Setterfield (2006a) as configuring macroeconomic policy so as to make inflation targeting fully compatible with the structure of the economy. Instead, it is precisely the sort of outcome that is feared by heterodox critics of inflation targeting (see, for example, Atesoglu and Smithin, 2006; Davidson, 2006; Michl, 2006).
} 
Hence the policy authorities are able to change and successfully pursue a new inflation target without this affecting the equilibrium of the real economy and hence their ability to achieve their stated output target. Note that, by the same token, it is also possible in the model above for the policy authorities to set and pursue an output target without fear of it having inflationary consequences. This is illustrated in Figure 2 below, which is again based on the isoclines in equations [7] and [8]. Increasing the output target from $y_{1}^{T}$ to $y_{2}^{T}$ causes an identical vertical displacement of both isoclines. The equilibrium configuration of the economy is thus altered, but only by virtue of a change in the equilibrium level of output consistent with the change in the policy authorities' output target. The equilibrium rate of inflation remains unchanged, equal to the authorities' (given) inflation target.

\section{[FIGURES 1\&2 GO HERE]}

\section{The Impact of Different Policy Reaction Functions}

We now turn to the impact of different policy reaction functions on the desirability of inflation targeting and the stability of macroeconomic equilibrium in a Post Keynesian economy. We adopt alternative specifications for the interest rate reaction function and the incomes policy reaction function (equations [3] and [4]) that differ from one another depending on whether they take into account the output target and/or the inflation target. Ultimately, there is a range of reaction functions that can result from the discretionary choices of the policy authorities, and the issue we wish to consider is to what extent these discretionary policy choices enhance or diminish the compatibility of inflation targeting with a Post Keynesian economy.

Let us first consider a situation in which the interest rate reaction function is given by equation [3], but the incomes policy reaction function in [4] is extended to include the output gap. The rationale for this extension is that $y$ affects $p$ in [2a], so it is reasonable for the policy authorities to manipulate $Z$ in anticipation of changes in $p$ when $y<y^{T}$. Formally, this extended incomes policy reaction function is given by:

$$
\dot{Z}=-\mu\left(p-p^{T}\right)-\psi\left(y-y^{T}\right)
$$

Since the interest rate reaction function is still described by equation [3], which implies that changes in real output are still given by equation [5], combination of equation [2a] with equations [4a] and [5] yields:

$$
\dot{p}=-(\theta \psi+\alpha \delta \lambda)\left(y-y^{T}\right)-\theta \mu\left(p-p^{T}\right)
$$

This variant of our model yields not only the same equilibrium values for output and inflation $\left(y^{*}=y^{T}\right.$ and $\left.p^{*}=p^{T}\right)$ as the basic model discussed in the previous section, but also an equilibrium configuration that is similarly stable. Indeed, this equilibrium configuration could be described by a figure similar to Figure 1, the only differences being that the $y$-intercept of the $\dot{p}=0$ isocline would now be closer to the origin and its slope would be flatter. As in the basic model of the previous section, then, the policy authorities can successfully pursue a lower inflation target without this affecting the equilibrium of the real economy and hence their ability to achieve their stated output target. Intuitively, this is because the extended incomes policy function, which incorporates the output gap, remains complimentary to the operation of the interest rate rule.

Let us now consider a situation in which we retain the incomes policy reaction function in equation [4], but extend the interest rate reaction function in [3] to include the inflation gap. Formally, this extended interest rate reaction function is given by:

$$
\dot{r}=\lambda\left(y-y^{T}\right)+\gamma\left(p-p^{T}\right)
$$

Equation [3a] is the sort of reaction function that would result from the discretionary policy choices of a monetary authority concerned with both output and inflation targets. Note that [3a] is close to a traditional 
Taylor rule, although there is no mention of a natural rate of interest in [3a] because, in keeping with Post Keynesian monetary theory, there is no such interest rate. With changes in real output now influenced by this extended interest rate rule, it follows from [1] and [3a] that:

$$
\dot{y}=-\delta \lambda\left(y-y^{T}\right)-\delta \gamma\left(p-p^{T}\right)
$$

which, given that our incomes policy reaction function is still given by equation [4], yields:

$$
\dot{p}=-\alpha \delta \lambda\left(y-y^{T}\right)-(\alpha \delta \gamma+\theta \mu)\left(p-p^{T}\right)
$$

We can solve for equilibrium by imposing the equilibrium conditions $\dot{y}=\dot{p}=0$ on equations [10] and [11], which yields the following isoclines:

$$
y=y^{T}+\frac{\gamma}{\lambda} p^{T}-\frac{\gamma}{\lambda} p
$$

and:

$$
y=\left(y^{T}+\frac{\alpha \delta \gamma+\theta \mu}{\alpha \delta \lambda} p^{T}\right)-\frac{\alpha \delta \gamma+\theta \mu}{\alpha \delta \lambda} p
$$

It follows directly from [12] and [13] that $y^{*}=y^{T}$ and $p^{*}=p^{T}$, with the equilibrium configuration so identified being stable. This can be verified by expressing [10] and [11] in matrix form as:

$$
\left[\begin{array}{c}
\dot{y} \\
\dot{p}
\end{array}\right]=\left[\begin{array}{cc}
-\delta \lambda & -\delta \gamma \\
-\alpha \delta \lambda & -(\alpha \delta \gamma+\theta \mu)
\end{array}\right]\left[\begin{array}{l}
y \\
p
\end{array}\right]+\left[\begin{array}{c}
\delta \lambda y^{T}+\delta \gamma p^{T} \\
\alpha \delta \lambda y^{T}+(\alpha \delta \gamma+\theta \mu) p^{T}
\end{array}\right]
$$

and noting that $|J|=\delta \lambda \theta \mu>0$ whilst $\operatorname{tr}(J)=-\delta(\lambda+\alpha \gamma)-\theta \mu<0$. In the economy described by equations [1], [2a], [3a] and [4], then, as in the situation described by the basic model in the previous section, the policy authorities set and pursue output and inflation targets that are, in turn, revealed to comprise the stable equilibrium configuration of the economy. Indeed, not only are the policy authorities able to both set and achieve an inflation target, they are able to do so without real costs in terms of the equilibrium level of output and hence without thwarting the achievement of any output target set independently of $p^{T}$. As is clear from Figure 3, decreasing the target rate of inflation (from $p_{1}^{T}$ to $p_{2}^{T}$, for instance) changes the equilibrium configuration of the economy, but only by altering the equilibrium rate of inflation in a manner consistent with the new inflation target. The equilibrium level of output remains consistent with the output $\operatorname{target}, y^{T}$. Unlike the situation described in Figure 1, however, with a lower inflation target both isoclines will now shift to the left, as is clear from equations [12] and [13]. ${ }^{20}$

\section{[FIGURE 3 GOES HERE]}

Let us now consider a situation in which the interest rate reacts to changes in the inflation gap, while the willingness and ability of workers to bid up the rate of growth of nominal wages reacts to changes in the output gap. In comparison with the basic model of the previous section, therefore, the gap to which each one of the policy instruments reacts is inverted. Here, we are modelling a central bank that is concerned solely with inflation, while the elected authority sees itself as attempting to increase labour market "flexibility" -

\footnotetext{
${ }^{20}$ As in the basic model of the previous section, increasing the output target (from $y_{1}^{T}$ to $y_{2}^{T}$, for instance) would also change the equilibrium configuration of the economy, but only by altering the equilibrium rate of output in a manner consistent with the new output target. The equilibrium level of inflation would remain consistent with the inflation target, $p^{T}$. Hence once again, the policy authorities could successfully pursue a new output target without this affecting their ability to achieve their stated inflation target.
} 
which in a Post Keynesian economy effectively means increasing worker insecurity and hence reducing the ability of workers to push for nominal wage increases - as $y$ rises (and hence unemployment falls), in the belief that such measures are essential to increasing the level of $y$ (and decreasing the level of unemployment) that will be permanently sustainable in the future. In other words, the state sees itself as pursuing supply-side policies designed to alter the "natural" level of real economic activity. ${ }^{21}$ This policy regime is a simplified version of the current policy orthodoxy (simplified because monetary policy is responsive only to $p$, in contrast to the standard Taylor rule), but operating in an explicitly Post Keynesian economy (as captured by our Phillips curve, which entertains a permanent direct relationship between inflation and output). And as the results below demonstrate, the consequences of this mixture (a simplified policy orthodoxy operating in a Post Keynesian economy) are adverse. Formally, the inverted policy reaction functions referred to above are given by:

$$
\dot{r}=\gamma\left(p-p^{T}\right)
$$

and:

$$
\dot{Z}=-\psi\left(y-y^{T}\right)
$$

It follows from [1] and [3b] that:

$$
\dot{y}=-\delta \gamma\left(p-p^{T}\right)
$$

Recall that equation $[2 \mathrm{a}]$ yields:

$$
\dot{p}=\alpha \dot{y}+\theta \dot{Z}
$$

Combining this expression with both [4b] and [14], we arrive at:

$$
\dot{p}=-\theta \mu\left(y-y^{T}\right)-\alpha \delta \gamma\left(p-p^{T}\right)
$$

We can now solve for equilibrium by imposing the conditions $\dot{y}=\dot{p}=0$ on equations [14] and [15]. This yields the isoclines:

$$
p=p^{T}
$$

and:

$$
y=\left(y^{T}+\frac{\alpha \delta \gamma}{\theta \mu} p^{T}\right)-\frac{\alpha \delta \gamma}{\theta \mu} p
$$

\footnotetext{
${ }^{21}$ It may be argued that the sort of structural adjustment policies that seek to increase labour market flexibility are usually pursued without reference to the business cycle (i.e., the proximity of $y$ to $y^{T}$ ). But our interpretation of the inverted $\dot{Z}$ reaction function above - which suggests that $y>y^{T}$ gives impetus to policies that claim to be increasing labour market flexibility - is quite plausible. Hence $y>y^{T}$ makes it easier to pursue labour market flexibility policies. The Clinton-era welfare reforms in the US, for example, were achieved at a time (during the late 1990s) when unemployment was below the estimated value of the NAIRU in the US (i.e., when output was above the target level implied by this estimated NAIRU). Alternatively, we might contrast the comparative ease with which a low unemployment/high (relative to potential) output economy such as Sweden has traditionally enforced strict rules with regard to the duration of unemployment insurance benefits with the problems faced by the French government in the spring of 2006 when it attempted to increase the ease with which young workers could be fired in a high unemployment/low (relative to potential) output economy. Empirical evidence supporting our interpretation of the inverted $\dot{Z}$ reaction function can be found in Howell et al (2007) and Elmeskov et al (1998), both of whom find that unemployment Granger causes the generosity of unemployment benefits. This result is further supported by Di Tella and MacCulloch (2002), whilst the OECD (2006) has reached the conclusion that high unemployment causes both increased unemployment benefit generosity and increased employment protection.
} 
It follows directly from [16] that $p^{*}=p^{T}$, and using this result in conjunction with [17] we find that $y^{*}=y^{T}$. However, note that the equilibrium configuration so identified is saddle-point unstable. This can be verified by writing [14] and [15] in matrix form as:

$$
\left[\begin{array}{c}
\dot{y} \\
\dot{p}
\end{array}\right]=\left[\begin{array}{cc}
0 & -\delta \gamma \\
-\theta \mu & -\alpha \delta \gamma
\end{array}\right]\left[\begin{array}{l}
y \\
p
\end{array}\right]+\left[\begin{array}{c}
\delta \gamma p^{T} \\
\theta \mu y^{T}+\alpha \delta \gamma p^{T}
\end{array}\right]
$$

and noting that despite $\operatorname{tr}(J)=-\alpha \delta \gamma<0$, we have $|J|=-\delta \gamma \theta \psi<0$. The substance of these results is as follows. In the economy described by equations [1], [2a], [3b] and [4b], the policy authorities set and pursue output and inflation targets that are, in turn, revealed to comprise the unstable equilibrium configuration of the economy. Hence, we have now lost what Setterfield (2006a) defines as the partial compatibility of inflation targeting with the underlying structure of the economy: the policy authorities are unable to both set and (in general) achieve an inflation target. Only if, by chance, the economy happens to be in the stable arm of the saddle-point will the equilibrium configuration $y^{*}=y^{T}$ and $p^{*}=p^{T}$ obtain. ${ }^{22}$ By the same token, it is only in this quite exceptional circumstance that what Setterfield (2006a) defines as the full compatibility of inflation targeting with the economy would be established. In short, a simplified policy orthodoxy regime in a Post Keynesian economy reduces the viability of inflation targeting.

This situation is depicted in Figure 4, which plots the isoclines given by equations [16] and [17]. It should be noted that two different inflation targets (for instance, $p_{1}^{T}>p_{2}^{T}$ ) will give rise to two different equilibrium configurations, each with $y^{*}=y^{T}$ and $p^{*}=p^{T}$. But both equilibria will be saddle-point unstable. Hence Figure 4 does not illustrate that the policy authorities can (in general) successfully choose between inflation targets. Instead, it shows only that different inflation targets imply different saddle-point unstable equilibrium configurations, with different equilibrium inflation rates corresponding to the same equilibrium output level.

\section{[FIGURE 4 GOES HERE]}

Similarly unstable equilibrium configurations will obtain in two other situations. The first one combines the inverted interest rate reaction function given by equation [3b] and the extended incomes policy reaction function given by equation [4a]. This situation is analogous to having a Post Keynesian elected authority (trying to use incomes policies to address inflation) combined with an independent central bank focused solely on inflation. The result is a policy regime involving an excessive focus on the part of the policy authorities on inflation: neither the elected authority nor the central bank has as its explicit objective the level of $y$. Hence although policy making in this regime is not strictly orthodox in its execution, the focus on inflation to the exclusion of real economic performance is.

While the rate of change of output in this case is given by [14], the rate of change of inflation must now be written as:

$$
\dot{p}=-\theta \psi\left(y-y^{T}\right)-(\alpha \delta \gamma+\theta \mu)\left(p-p^{T}\right)
$$

\footnotetext{
${ }^{22}$ Recall that our model is only conditionally or provisionally closed and that the true underlying decision making environment is one of fundamental uncertainty. Since self-aware decision makers understand this (albeit to a degree that will vary between individuals depending on what Dequech (2000) calls their "uncertainty perception"), we would not expect decision makers to spontaneously "jump" onto this stable arm - as might be expected in a system in which closure is absolute and decision makers form rational expectations. The likely instability of the system described above will thus not be automatically resolved, with the result that stability in this system is a special case. It also follows that any "tensions" - be they logical or socio-political - that arise as the result of instability must be addressed by processes from which the model developed above abstracts and that are beyond the scope of this paper. Once again we are reminded here that we are dealing with an open system and that our model is necessarily a local approximation of this larger system.
} 
As in the previous scenario, the equilibrium configuration is given by $p^{*}=p^{T}$ and $y^{*}=y^{T}$, this equilibrium being saddle-point unstable. The system could be illustrated by a figure similar to Figure 4 , the only differences (assuming that $\mu \approx \psi$ ) being that the $p$-intercept of the $\dot{p}=0$ isocline would now be closer to the origin and its slope would be flatter. In the Jacobian matrix of this system, we would observe $J_{22}=$ $-(\alpha \delta \gamma+\theta \mu)$, capturing the intuition that the inclusion of the inflation gap in the incomes policy reaction function now reinforces the operation of the interest rate rule, so that what is driving instability is the excessive focus of the policy regime on combating inflation.

Another situation similar to that depicted in Figure 4 combines the extended interest rate reaction function given by equation [3a] and the inverted incomes policy reaction function given by equation [4b]. This situation is akin to a fuller version of the current policy orthodoxy, in which the central bank's interest rate operating procedure responds to variations in both $p$ and $y$, with the state otherwise focused on pursuing labour market "flexibility" (or, as we would have it, worker insecurity). As it turns out, while the rate of change in output is given by [10], the rate of change of inflation is given by:

$$
\dot{p}=-(\alpha \delta \lambda+\theta \psi)\left(y-y^{T}\right)-\alpha \delta \gamma\left(p-p^{T}\right)
$$

We can solve for equilibrium by imposing the conditions $\dot{y}=\dot{p}=0$ on equations [10] and [19]. While the isocline corresponding to the former condition is given by equation [12], the isocline corresponding to the latter is given by:

$$
y=\left(y^{T}+\frac{\alpha \delta \gamma}{\alpha \delta \lambda+\theta \psi} p^{T}\right)-\frac{\alpha \delta \gamma}{\alpha \delta \lambda+\theta \psi} p
$$

It follows directly from [12] and [20] that $y^{*}=y^{T}$ and $p^{*}=p^{T}$, with the equilibrium configuration so identified once again being saddle-point unstable. As compared with the situation described in Figure 3, because the incomes policy reaction function ceases to depend on the inflation gap (depending instead on the output gap), the equilibrium configuration of the economy ceases to be stable. This can be verified by expressing [10] and [19] in matrix form as:

$$
\left[\begin{array}{c}
\dot{y} \\
\dot{p}
\end{array}\right]=\left[\begin{array}{cc}
-\delta \lambda & -\delta \gamma \\
-(\alpha \delta \lambda+\theta \psi) & -\alpha \delta \gamma
\end{array}\right]\left[\begin{array}{l}
y \\
p
\end{array}\right]+\left[\begin{array}{c}
\delta \lambda y^{T}+\delta \gamma p^{T} \\
(\alpha \delta \lambda+\theta \mu) y^{T}+\alpha \delta \gamma p^{T}
\end{array}\right]
$$

and noting that $|J|=-\delta \gamma \theta \psi<0$ despite $\operatorname{tr}(J)=-\delta(\lambda+\alpha \gamma)<0$. In the economy described by equations [1], [2a], [3a] and [4b], then, the policy authorities set and pursue output and inflation targets that are, in turn, revealed to comprise the unstable equilibrium configuration of the economy. As in the situation depicted in Figure 3, we forego (in general) even the partial compatibility of inflation targeting with the underlying structure of the economy, because the policy authorities are unable to both set and automatically achieve an inflation target. The latter will only prove possible in the case where the economy happens, by chance, to be on the stable arm of the saddle-point equilibrium configuration $y^{*}=y^{T}$ and $p^{*}=p^{T}$.

This situation is depicted in Figure 5, which is similar to Figure 3. The major difference is that the $\dot{p}=0$ isocline is now flatter than the $\dot{y}=0$ isocline, as implied by equations [12] and [20]. As in the situation described in Figure 3, any two different inflation or output targets will give rise to two different equilibrium configurations, both consistent with $y^{*}=y^{T}$ and $p^{*}=p^{T}$. But both equilibria will be saddlepoint unstable. Hence, as before, the policy authorities cannot simply choose between two different inflation or output targets. Rather, a higher (lower) output (inflation) target merely implies a different saddle-point unstable (and therefore generally unachievable) equilibrium configuration with the same inflation (output) level and a proportionally higher (lower) output (inflation) level. 


\section{[FIGURE 5 GOES HERE]}

A further permutation that merits attention involves the situation in which both the interest rate reaction function and the incomes policy reaction function respond to both the output gap and the inflation gap, as in equations [3a] and [4a]. This scenario is consistent with Post Keynesian policy making on the part of both the central bank and the elected authorities, but both policy instruments are now being adjusted in response to both policy objectives (in contrast with policy making in the original model in section 2, which involves the dedicated adjustment of each policy instrument in response to just one objective). As the following results show, this less precisely focused pursuit of policy can be dangerous, depending on the size of the policy reaction coefficients. Hence, while the rate of change of output is given by equation [10], the rate of change of inflation is now given by:

$$
\dot{p}=-(\alpha \delta \lambda+\theta \psi)\left(y-y^{T}\right)-(\alpha \delta \gamma+\theta \mu)\left(p-p^{T}\right)
$$

We can solve for equilibrium by imposing the conditions $\dot{y}=\dot{p}=0$ on equations [10] and [21]. While the isocline corresponding to the former condition is given by equation [12], the isocline corresponding to the latter is given by:

$$
y=\left(y^{T}+\frac{\alpha \delta \gamma+\theta \mu}{\alpha \delta \lambda+\theta \psi} p^{T}\right)-\frac{\alpha \delta \gamma+\theta \mu}{\alpha \delta \lambda+\theta \psi} p
$$

It follows directly from [12] and [22] that $y^{*}=y^{T}$ and $p^{*}=p^{T}$, with the equilibrium configuration so identified being either stable or saddle-point unstable. This can be verified by expressing [10] and [21] in matrix form as:

$$
\left[\begin{array}{c}
\dot{y} \\
\dot{p}
\end{array}\right]=\left[\begin{array}{cc}
-\delta \lambda & -\delta \gamma \\
-(\alpha \delta \lambda+\theta \psi) & -(\alpha \delta \gamma+\theta \mu)
\end{array}\right]\left[\begin{array}{l}
y \\
p
\end{array}\right]+\left[\begin{array}{c}
\delta \lambda y^{T}+\delta \gamma p^{T} \\
(\alpha \delta \lambda+\theta \mu) y^{T}+(\alpha \delta \gamma+\theta \psi) p^{T}
\end{array}\right]
$$

and noting that $|J|=\delta \theta(\lambda \mu-\gamma \psi)>>0$ despite $\operatorname{tr}(J)=-\delta(\lambda+\alpha \gamma)-\theta \mu<0$. In the economy described by equations [1], [2a], [3a] and [4a], therefore, the policy authorities set and pursue output and inflation targets that are, in turn, revealed to comprise the stable (unstable) equilibrium configuration of the economy in the case where $\lambda \mu-\gamma \psi>0(\lambda \mu-\gamma \psi<0)$. In other words, we need $\lambda \mu$ to be large relative to $\gamma \psi$ to secure macroeconomic stability. Intuitively, comparing the reaction functions [3a] and [4a] to their original forms in [3] and [4], what this means is that we need the original orientations of monetary and incomes policy (adjusting to $y$ and $p$ respectively) to dominate their extended orientations (responding to $p$ and $y$ respectively).] Hence, whether or not we observe either the partial or full compatibility of inflation targeting with the underlying structure of the economy depends on the sign of $\lambda \mu-\gamma \psi$. While the stable equilibrium configuration is described by a figure similar to Figure 3, the unstable equilibrium configuration is described by a figure similar to Figure 5 .

As a final exercise, we consider the case where the central bank's interest rate operating procedure is:

$$
r=r^{*}+\lambda\left(y-y^{T}\right)+\gamma\left(p-p^{T}\right)
$$

where, in keeping with the result in section 2:

$$
r^{*}=\frac{y_{0}-y^{T}}{\delta}
$$

In this scenario, the central bank fancies itself to be using a Taylor rule based on the "natural" rate of interest and "natural" level of output, but these latter values are, in fact, social constructions: both are subjective 
targets (determined by $y^{T}$ ) masquerading in the minds of central bankers as objective features of the economy. $^{23}$

From the above equation for $r$, it follows that:

$$
\dot{r}=\lambda \dot{y}+\gamma \dot{p}
$$

This monetary policy reaction function - in tandem with the inverted incomes policy reaction function, [4b] provides perhaps the best approximation of current policy orthodoxy. We will thus refer to this policy regime as one of full policy orthodoxy.

In order to establish the consequences of full policy orthodoxy for the macroeconomic stability of a Post Keynesian economy, we need only combine the policy reaction functions in [3c] and [4b] with equations [1] and [2a] from our original model. In so doing, we arrive at the following system of simultaneous differential equations:

$$
\begin{aligned}
& \dot{y}=\frac{\delta \gamma \theta \mu}{1+\delta(\lambda+\alpha \gamma)}\left(y-y^{T}\right) \\
& \dot{p}=\theta \mu\left(\frac{\alpha \delta \gamma}{1+\delta(\lambda+\alpha \gamma)}-1\right)\left(y-y^{T}\right)
\end{aligned}
$$

Under the equilibrium conditions $\dot{y}=\dot{p}=0$, equations [23] and [24] yield one and the same isocline:

$$
y=y^{T}
$$

It follows directly from [25] that $y^{*}=y^{T}$, but the equilibrium rate of inflation is apparently indeterminate. If, however, the central bank is serious about its inflation target, only one of the potentially multiple equilibrium rates of inflation consistent with $y^{*}=y^{T}$ - specifically, the value $p^{*}=p^{T}$ - will constitute a "fully adjusted position".

Unfortunately, however, none of the equilibria of this system are stable. This claim can be verified by expressing [23] and [24] in matrix form, as:

$$
\left[\begin{array}{c}
\dot{y} \\
\dot{p}
\end{array}\right]=\left[\begin{array}{cc}
\frac{\delta \gamma \theta \mu}{1+\delta(\lambda+\alpha \gamma)} & 0 \\
\theta \mu\left(\frac{\alpha \delta \gamma}{1+\delta(\lambda+\alpha \gamma)}-1\right) & 0
\end{array}\right]\left[\begin{array}{l}
y \\
p
\end{array}\right]+\left[\begin{array}{c}
\frac{-\delta \gamma \theta \mu}{1+\delta(\lambda+\alpha \gamma)} y^{T} \\
-\theta \mu\left(\frac{\alpha \delta \gamma}{1+\delta(\lambda+\alpha \gamma)}-1\right) y^{T}
\end{array}\right]
$$

Note that whilst $|J|=0, \operatorname{tr}(J)=\frac{\delta \gamma \theta \mu}{1+\delta(\lambda+\alpha \gamma)}>0$. Taken in conjunction with our earlier results regarding the stability implications of policy regimes corresponding to simplified and fuller versions of the current policy orthodoxy, the results above for the full policy orthodoxy regime suggest that in a Post Keynesian economy, the more orthodox the policy blend becomes, the worse are the consequences for macroeconomic stability and hence the viability of inflation targeting.

\section{Conclusions}

The purpose of this paper has been to build on Setterfield's (2006a) Extended Post Keynesian Model (EPKM), which purports to demonstrate the potential compatibility of inflation targeting with a Post Keynesian macroeconomic environment. We extend the EPKM in two ways: first, by introducing an explicitly Post Keynesian theory of inflation expectations; and second, by considering a variety of policy

\footnotetext{
${ }^{23}$ See Smithin (2004) for further discussion of this process of socially constructing "natural" rates and levels of economic activity.
} 
reaction functions that may result from the discretionary intervention in the economy of both monetary and non-monetary policy authorities.

Our results corroborate Setterfield's (2006a) claim that, with the correct policy mix, it is possible to make inflation targeting fully compatible with the operation of a Post Keynesian economy. In other words, it is quite possible for the policy authorities to both set and achieve an inflation target without real costs (i.e., without thwarting the achievement of any target level of real activity set independently of the inflation target). Indeed, our results suggest that in achieving this full compatibility of inflation targeting with the structure of a Post Keynesian economy, policy makers have more latitude in the design of policy than was originally envisaged by Setterfield (2006a).

A second and equally important conclusion pertains to limits to the policy-making latitude alluded to above. The results in this paper suggest that policies that are orthodox in either their design and execution or even their essential orientation (with regard to the privileging of inflation over real economic outcomes) are ill-suited to a Post Keynesian economy. More specifically, the more orthodox the policy blend becomes in a Post Keynesian economy, the more adverse are the consequences for both macroeconomic stability and the viability of inflation targeting.

\section{References}

Akerlof, G.A., W.T. Dickens and G.L. Perry (2000) "Near-rational wage and price setting and the long run Phillips curve," Brookings Papers on Economic Activity, 1, 1-60

Agliari, A. C. Chiarella and L. Gardini (2006) "A re-evaluation of adaptive expectations in light of global non-linear dynamic analysis," Journal of Economic Behavior and Organization, 60, 526-52

Atesoglu, H.S. and J. Smithin (2006) "Inflation targeting in a simple macroeconomic model," Journal of Post Keynesian Economics, 28, 673-88

Burdekin, R.C.K. and P. Burkett (1996) Distributional Conflict and Inflation: Theoretical and Historical Perspectives, London, Macmillan

Chick, V. (2002) "An equilibrium of action: A new approach to the long period in Keynes," University College London, mimeo.

Chick, V. and M. Caserta (1997) "Provisional equilibrium in macroeconomic theory," in P. Arestis, G. Palma and M. Sawyer (eds) Markets, Unemployment and Economic Policy: Essays in Honour of Geoff Harcourt, Volume Two, London, Routledge

Colander, D. (ed.) (1986) Incentive-Based Incomes Policies: Advances in TIP and MAP, Cambridge, MA, Harper and Row, Ballinger

Cornwall, J. and W. Cornwall (2001) Capitalist Development in the Twentieth Century, Cambridge, Cambridge University Press

Davidson, P. (2006) "Can, or should, a central bank inflation target?" Journal of Post Keynesian Economics, 28, 689-703

Dequech, D. (2000) “Asset choice, liquidity preference, and rationality under uncertainty," Journal of Economic Issues, 54, 159-76

Di Tella, R. and R.J. MacCulloch (2002) "The determination of unemployment benefits," Journal of Labor Economics, 20, 404-34

Elmeskov, J., J. Martin and S. Scarpetta (1998) "Key lessons for labour market reforms: evidence from OECD countries' experience," Swedish Economic Policy Review, 5, 205-52

Fair, R. (1999) "Estimated inflation costs had European unemployment been reduced in the 1980s by macroeconomic policies," Journal of Macroeconomics, 21, 1-28

Fair, R. (2000) "Testing the NAIRU model for the United States," Review of Economics and Statistics, 82, 64-71

Gerrard, B. (1995) "Probability, uncertainty and behaviour: a Keynesian perspective," in S. Dow and J. Hillard (eds) Keynes, Knowledge and Uncertainty, Aldershot, Edward Elgar 
Howell, D.R., D. Baker, A. Glyn and J. Schmitt (2007) "Are protective labor market institutions at the root of unemployment? A critical review of the evidence," Capitalism and Society, forthcoming

Kalecki, M. (1971) Selected Essays on the Dynamics of the Capitalist Economy, Cambridge, Cambridge University Press

Kapadia, S. (2005) "Inflation target expectations and optimal monetary policy," Oxford University Department of Economics Working Paper No. 227

Keynes, J.M. (1936) The General Theory of Employment, Interest and Money, London, Macmillan

Keynes, J.M. (1937) "The General Theory of Employment," Quarterly Journal of Economics, 51, 209-23

Kregel. J. (1976) "Economic methodology in the face of uncertainty", Economic Journal, 86, 209-25

Lavoie, M. (1992) Foundations of Post-Keynesian Economic Analysis, Aldershot, Edward Elgar

Lawson, T. (1995) “The 'Lucas critique': a generalisation," Cambridge Journal of Economics, 19, 257-76

Lima, G.T. (2004) "Power and conflict in macro-policy making: a note on a political economy of an incomes policy," Brazilian Journal of Political Economy, 24, 514-22

Michl, T. (2006) "Tinbergen Rules the Taylor Rule," Levy Economics Institute of Bard College, Working Paper No.444

Mishkin, F.S (2002) "Inflation targeting," in B. Snowdon and H.R. Vane (eds) An Encyclopedia of Macroeconomics, Cheltenham, Edward Elgar, pp.361-5

OECD (2006) "Political economy of structural reform," Working Paper No. 1 on Macroeconomic and Structural Policy Analysis, Paris, OECD

Palley, T.I. (2003) "The backward-bending Phillips curve and the minimum unemployment rate of inflation: wage adjustment with opportunistic firms," Manchester School, 71, 35-50

Palley, T.I. (2006a) "A Post Keynesian framework for monetary policy: why interest rate operating procedures are not enough," in L.P. Rochon and C. Gnos (eds) Economic Policies: Perspectives from the Keynesian Heterodoxy, Cheltenham, Edward Elgar

Palley, T.I. (2006b) "The economics of inflation targeting," paper presented at the Meetings of the Eastern Economic Association, Philadelphia, February 24-26, 2006

Rochon, L.P. and S. Rossi (2006) "Inflation targeting, economic performance and income distribution: a monetary macroeconomics analysis," Journal of Post Keynesian Economics, 28, 615-38

Rowthorn, R. (1977) "Conflict, inflation and money", Cambridge Journal of Economics, 1, 215-39

Sawyer, M. (2006) "Inflation targeting and central bank independence: we are all Keynesians now! Or are we?" Journal of Post Keynesian Economics, 28, 639-52

Setterfield, M.A. (1997a) "Should economists dispense with the notion of equilibrium?" Journal of Post Keynesian Economics, 20, 47-76

Setterfield, M. (2003) "Critical realism and formal modelling: incompatible bedfellows?", in P. Downward (ed.) Applied Economics and the Critical Realist Critique, London, Routledge

Setterfield, M. (2006a) "Is Inflation Targeting Compatible with Post Keynesian Economics?" Journal of Post Keynesian Economics, 28, 653-71

Setterfield, M. (2006b) "The Rise, Decline and Rise of Incomes Policies in the US During the Post-War Era: An Institutional-Analytical Explanation of Inflation and the Functional Distribution of Income," Journal of Institutional Economics, forthcoming

Setterfield, M. and K. LeBlond (2003) "The Phillips curve and US macroeconomic performance during the 1990s," International Review of Applied Economics, 17, 361-76

Smithin, J. (2004) "Interest rate operating procedures and income distribution," in M. Lavoie and M. Seccareccia (eds) Central Banking in the Modern World: Alternative Perspectives, Cheltenham, Edward Elgar, pp. 57-69

Stanley, T.D. (2005) "Integrating the empirical tests of the natural rate hypothesis: a meta-regression analysis," Kyklos, 58, 611-34

Tinbergen, J. (1952) On the Theory of Economic Policy, Amsterdam, North Holland Press, $2^{\text {nd }}$ Edition

Wallich, H.C. and S. Weintraub (1971) “A tax-based incomes policy," Journal of Economic Issues, 5, 1-19 


\section{Appendix I: Deriving the Short Run Phillips Curve}

The Phillips curve in equation [2] is based on the following conflicting-claims model of the inflation process:

$$
\begin{array}{ll}
w=\tau\left[\left(\omega_{W}-\omega\right)+q+p^{e}\right] & , \quad 0<\tau<1 \\
p=\rho\left(\omega-\omega_{F}\right)+w-q, & 0<\rho<1 \\
\tau=\tau_{y} y+\tau_{Z} Z &
\end{array}
$$

where $w$ is nominal wage growth, $\omega_{W}$ is the target wage share of workers, $\omega$ is the actual wage share, $q$ is the rate of growth of labour productivity, $\omega_{F}$ is the target wage share of firms (where $\omega_{W}>\omega_{F}$ by assumption), and all other variables are as previously defined. Equation [A1] describes nominal wage growth as a function of the difference between workers' target wage share and the actual wage share (the former representing their distributional aspirations), the rate of productivity growth and expected inflation (both of which, ceteris paribus, will affect the wage share unless the nominal wage is adjusted in compensating fashion). The parameter $\tau$ represents the relative power of workers vis a vis firms in the wage bargain. As seen in equation [A3], $\tau$ varies directly with real output, ${ }^{24}$ and institutional features of the labour market (including labour law, trade union representation, the structure of the employment relation and so forth) that affect the ability and willingness of workers to seek nominal wage increases.

Equation [6] states that inflation depends upon the rate of growth of unit labour costs $(w ! q)$ and the difference between the actual wage share and firms' target wage share. The parameter $\rho$ is determined by the state of competition in product markets and the corresponding ability of firms to mark up prices in excess of the average costs of production. ${ }^{25}$ In fact, equation [6] is essentially a dynamic version of a standard mark-up pricing equation in which the mark up (and hence $\omega_{F}$ ) is determined by the target rate of return on firms' assets (see Setterfield, 2006).

The conflicting-claims model above reflects three important features of PK macroeconomics. First, wage bargaining is conducted in nominal terms (equation [A1]). Second, the real wage is determined in the goods market by the pricing decisions of firms ${ }^{26}$ Finally, there is an absence of full indexation in both wage and price setting behaviour $(0<\tau, \rho<1)$. This means that neither workers nor firms always have sufficient market power to fully incorporate wage share aspirations (and, in the case of workers, productivity growth and inflation expectations) into final wages and prices. ${ }^{27}$

Assuming that $q=0$, equations [A1] and [A2] can be re-written as:

$$
w=\tau\left[\left(\omega_{W}-\omega\right)+p^{e}\right]
$$

and:

$$
p=\rho\left[\left(\omega-\omega_{F}\right)+w\right]
$$

\footnotetext{
${ }^{24}$ It is assumed in the model above that the economy generally operates with under-utilized labour and capital resources due to effective demand failures, so that variations in $y$ (given the current level of labour productivity) reflect the proximity of the real economy to its potential output.

${ }^{25}$ In this way, $\rho$ is analogous to Kalecki's (1971) degree of monopoly, and will therefore be influenced by factors such as the concentration of domestic markets, the price elasticity of demand for final output and the amount of international competition faced by firms.

${ }^{26}$ To see this, note that by re-arranging [A2] above we get:

$$
w-p=q-\rho\left(\omega_{W}-\omega_{F}\right)
$$

- i.e., the rate of growth of the real wage is independent of the relative power of workers in the wage bargain $(\tau)$ and workers target wage share $\left(\omega_{W}\right)$.

${ }^{27}$ Workers failure to fully incorporate inflation expectations into nominal wage growth may reflect not only incomplete bargaining power, but also incomplete real wage resistance due to "near rationality" (Palley, 2003, 2006a; Akerlof et al, 2000).
} 
One of the necessary conditions for equilibrium in the resulting model is that $\omega=\bar{\omega}$ which, from the definition of the wage share, implies that $p=w .{ }^{28}$ Imposing this equilibrium condition on [A5], we arrive at:

$$
\omega=\omega_{F}
$$

Imposing the same equilibrium condition on [A4], and bearing in mind the result derived in [A6], we arrive at:

$$
p=\tau\left[\left(\omega_{W}-\omega_{F}\right)+p^{e}\right]
$$

Finally, combining [A9] with [A3], we arrive at:

$$
p=\left[\tau_{y} y+\tau_{z} Z\right]\left[\left(\omega_{W}-\omega_{F}\right)+p^{e}\right]
$$

Taking the wage share targets $\omega_{W}$ and $\omega_{F}$ as exogenously given, [A10] describes a short run Phillips curve in which inflation varies positively in $y, Z$ and $p^{e}$, ceteris paribus. Equation [2] in the main body of this paper which has identical properties - can therefore be considered a linear approximation of [A10], with $\varphi<1$ capturing both (a) the incomplete bargaining power of workers and (b) incomplete real wage resistance due to near rationality, as discussed above. Note that $\varphi<1$ is also consistent with empirical evidence showing that, in empirical estimates of [2], the power of the hypothesis test $\mathrm{H}_{0}: \varphi=1$ is unimpressive, since failure to reject this null hypothesis is associated with very large Type II errors (Setterfield and LeBlond, 2003). It is also consistent with evidence showing that the inflation costs of an increase in real economic activity are strictly finite, contrary to the predictions of the accelerationist hypothesis embodied in $\varphi=1$ (Fair, 1999, 2000). Finally, it is consistent with exercises in meta-analysis that reject the hypothesis - contingent on $\varphi=1$ - that there exists a unique rate of unemployment consistent with constant inflation (Stanley, 2005).

\section{Figure 1: Inflation Targeting Without Sacrificing Output}

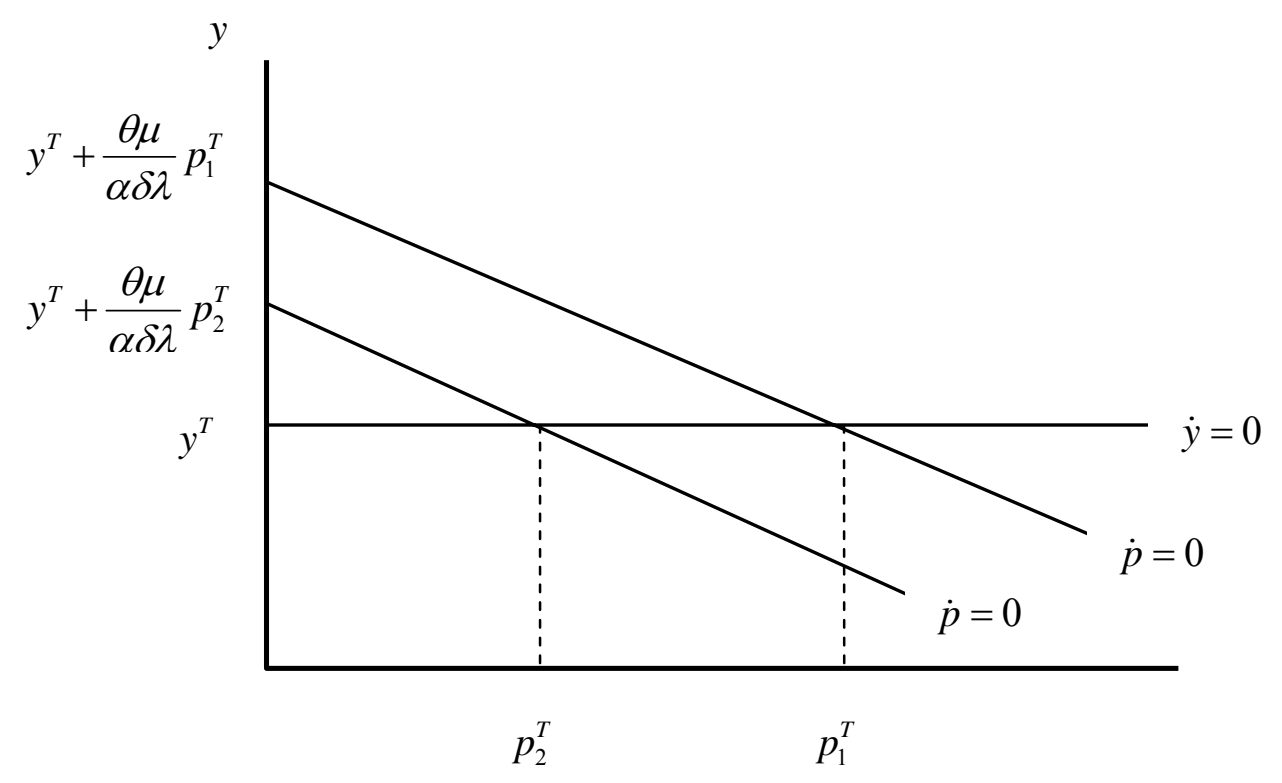

\footnotetext{
${ }^{28}$ The second equilibrium condition - which states that $p=p^{e}-$ is overlooked here, since our ambition is to derive a short-run Phillips curve consistent with equation [2].
} 
Figure 2: Output Targeting Without Increasing Inflation

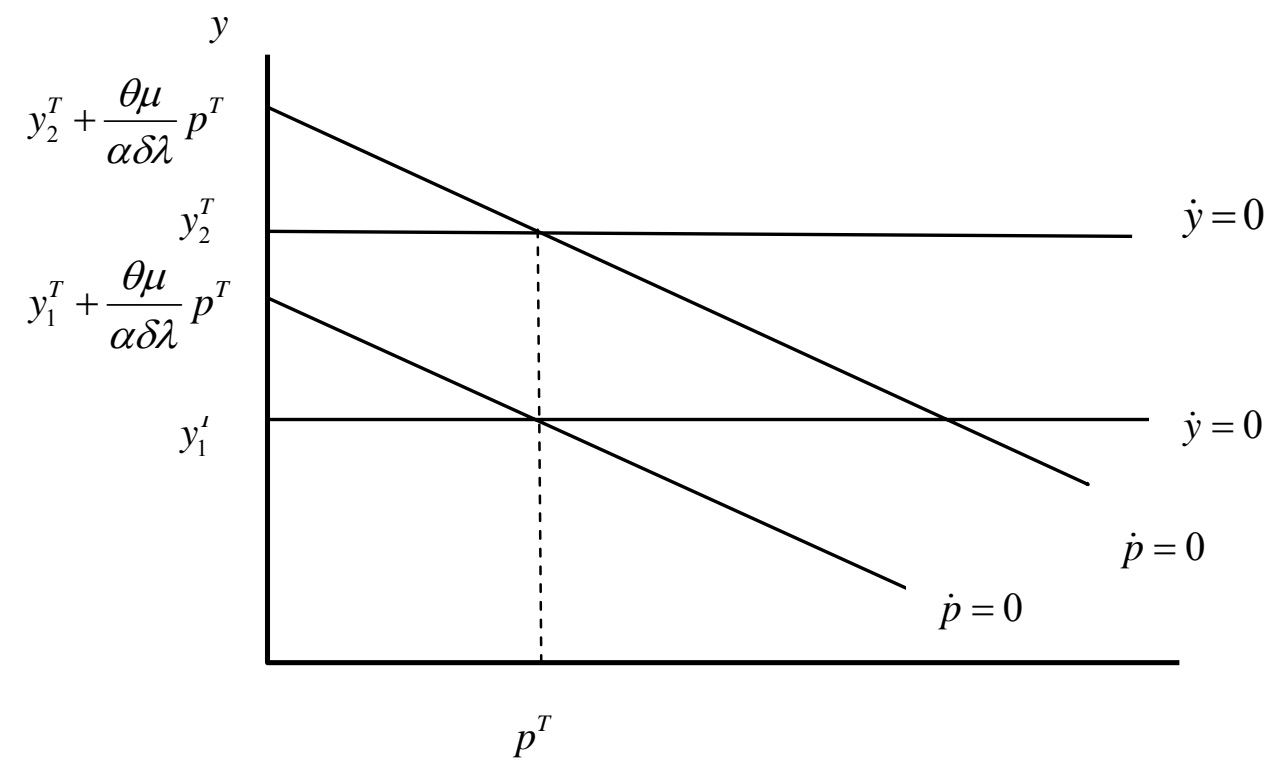

Figure 3: Inflation Targeting when Both Policy Instruments are Sensitive to the Output Gap

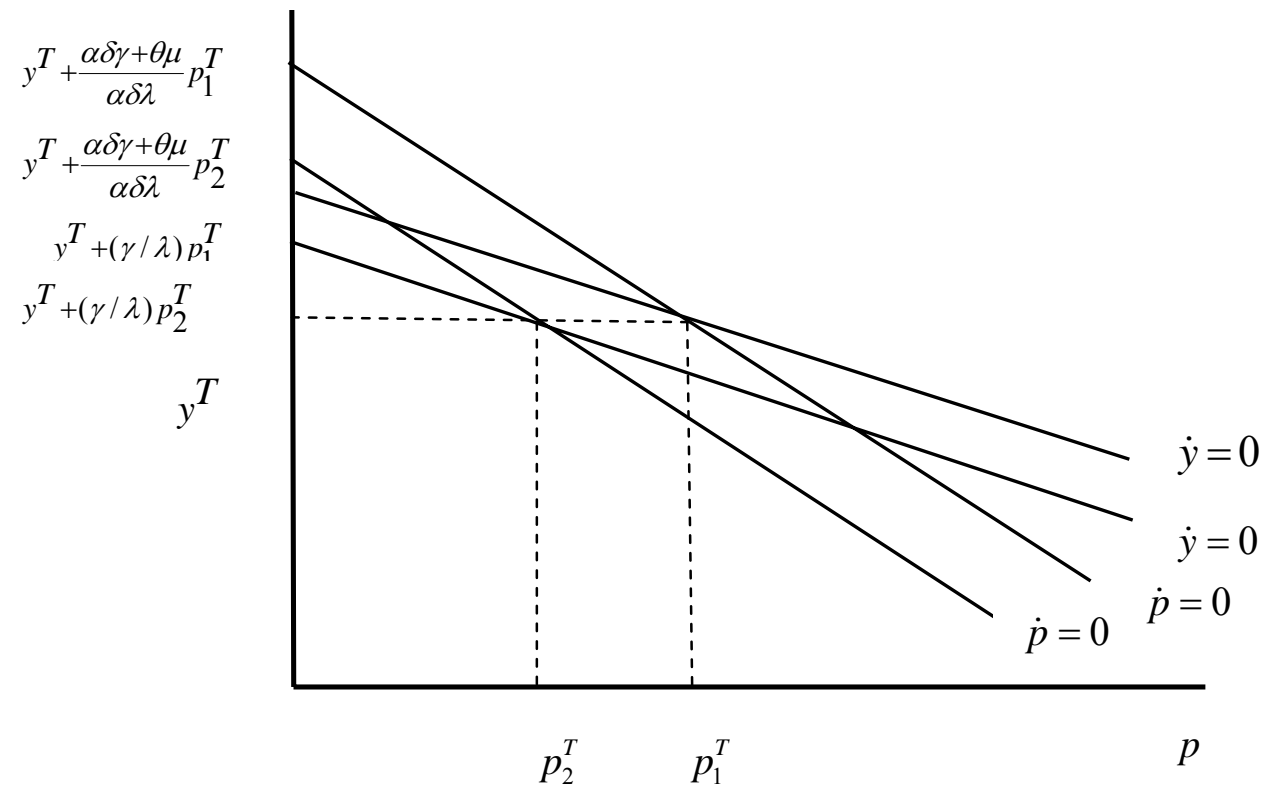


Figure 4: Simplified Policy Orthodoxy in a Post Keynesian Economy

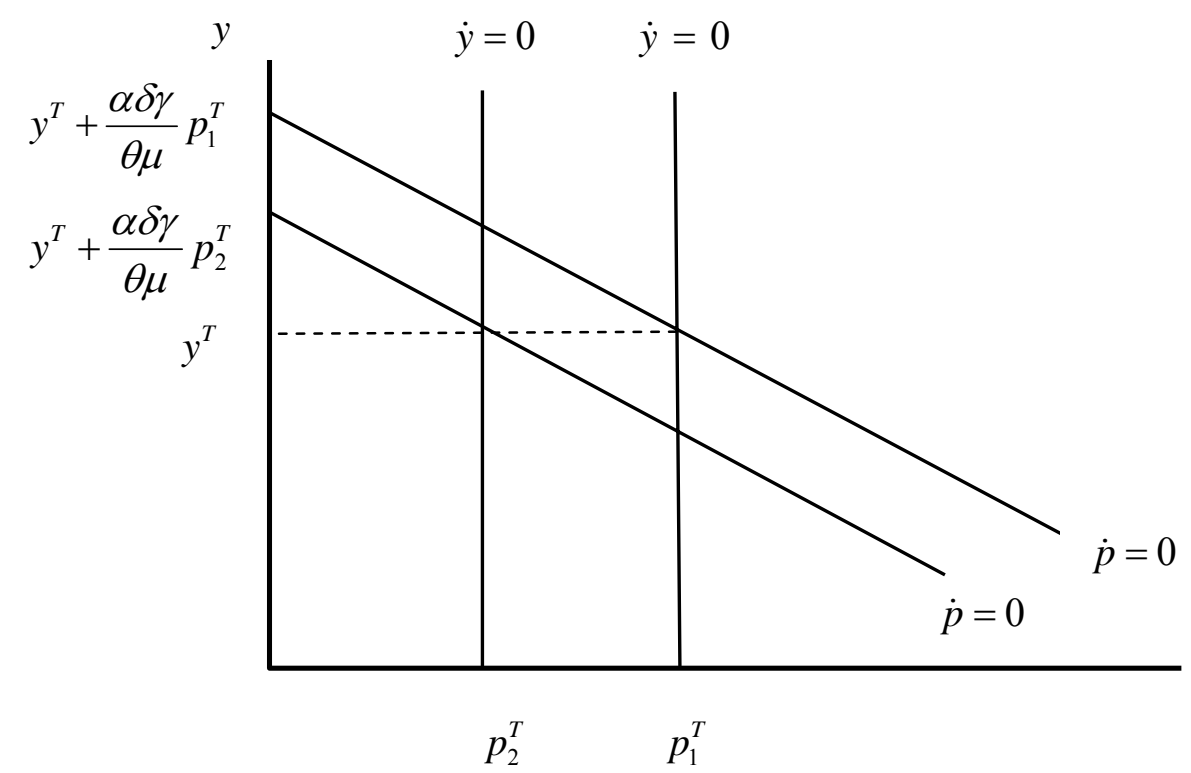

Figure 5: “Fuller” Policy Orthodoxy in Post Keynesian Economy

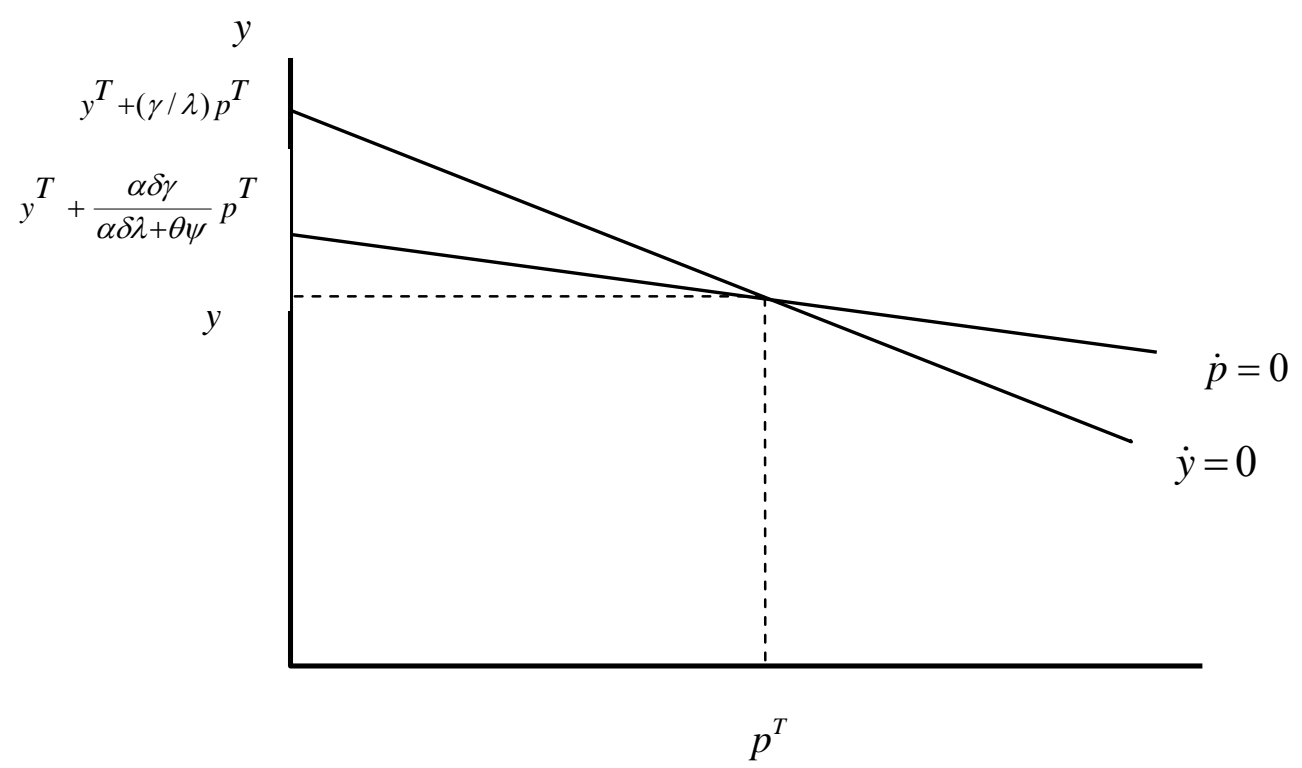

